\title{
Assessoria executiva em arquivos: relato das percepções acadêmicas de um projeto de extensão universitária
}

\author{
Luciane Fontana Matoso Silva \\ Mestranda em Administração na Universidade Estadual do Centro-Oeste (Unicentro). \\ Professora Colaboradora nos Cursos de Secretariado Executivo e Contabilidade da Unicentro. \\ E-mail: luciane1712@hotmail.com (Brasil)
}

\section{Resumo}

Além de possibilitar a formação do profissional cidadão, a extensão universitária credencia-se, cada vez mais, junto à sociedade, como espaço privilegiado de produção do conhecimento significativo para a superação das desigualdades sociais existentes. Com vistas ao aprendizado acadêmico das práticas secretariais, o projeto de extensão Assessoria Executiva em Arquivos procurou incentivar os acadêmicos do curso de Secretariado Executivo a disseminar conhecimentos pertinentes às técnicas de arquivamento por meio da assessoria nas organizações. Nesse sentido, um processo de assessoria executiva foi implementado nos arquivos de um departamento de uma universidade pública do estado do Paraná e, a partir do projeto citado, indagou-se: Como a assessoria em arquivos pode contribuir para a formação do profissional de secretariado executivo? Esse questionamento direcionou para o objetivo geral deste artigo, que foi relatar a percepção dos acadêmicos de Secretariado Executivo de uma universidade pública do Paraná durante a participação do Projeto de Extensão Assessoria Executiva em Arquivos. Os objetivos específicos do estudo foram: a) identificar as percepções acadêmicas a respeito da experiência da assessoria em arquivos; e b) evidenciar o profissional de secretariado executivo como gestor documental nas organizações. Para tanto, a partir de um estudo de caso, a pesquisa contou com uma metodologia qualitativa e de natureza descritiva, em que foram coletados relatos dos discentes participantes do projeto a partir da técnica de observação participante, da triangulação dos dados e da análise de conteúdo. A assessoria prestada evidenciou que a prática do secretariado possibilita ao profissional de secretariado executivo orientar e acompanhar a implementação de planos de arquivo, além de compartilhar seus conhecimentos adquiridos no ambiente acadêmico.

Palavras-chave: Arquivo. Assessoria Executiva. Secretariado Executivo. 


\title{
Executive advisory on archives: report of academic perceptions in a project of university extension
}

\begin{abstract}
The university extension enables the formation of professional and citizen accredits, increasingly, to society as a privileged space of production of significant knowledge for overcoming social inequalities. With a view to academic learning of secretarial practices, the extension project Executive Advisory Archives sought to encourage the academic course of the Executive Secretary to disseminate relevant knowledge to archival techniques through assistance in organizations. In this sense, there was executive assistance in the archives of a department of a public university of Paraná. From the design cited was asked: "- How the advice archives can contribute to the formation of the professional executive secretariat" The aim of this paper was to report the perception of the Executive Secretariat academics at a public university of Paraná during participation Extension Project Executive Advisory Archives. The specific objectives were: a) identify the academic perceptions about the experience of advising on archives b) show the professional executive secretariat as document manager in organizations. In this study, we used the qualitative research study with the case of a descriptive nature. We collected reports of students participating in the project, we used participant observation technique, in addition to the triangulation of data and content analysis. The advice provided showed that the practice of the secretariat allows the executive secretary professional to guide and monitor the implementation of archival plans, as well as share their knowledge acquired in the academic environment.
\end{abstract}

Keywords: Archive. Executive advisory. Executive secretariat.

\section{Como referenciar em APA:}

Silva, L. F. M. (2019). Assessoria executiva em arquivos: relato das percepções acadêmicas de um projeto de extensão universitária. R.G.Secr.,GESEC, 10(1), 73-90.

\section{Como referenciar em ABNT:}

Silva, L. F. M. (2019). Assessoria executiva em arquivos: relato das percepções acadêmicas de um projeto de extensão universitária. R.G.Secr.,GESEC, São Paulo, v. 10, n. 1, p. 73-90, jan.abr. 2019.
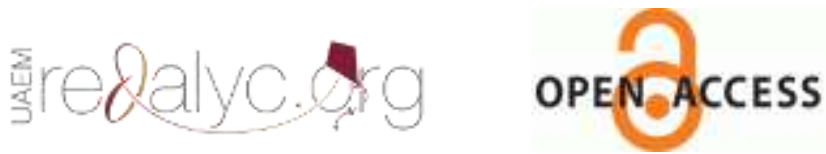


\section{Introdução}

A organização dos arquivos é um tema questionável para muitas instituições por se tratar de um trabalho contínuo, dispendioso de tempo e de técnicas eficientes. Isso porque, devido à falta de conhecimento e conscientização, ainda há profissionais que entendem a gestão dos arquivos como a separação de documentos, bem como sua guarda em salas separadas ou almoxarifados. Diante disso, as organizações precisam reconhecer o valor das informações e dos documentos que tramitam diariamente com suas atividades e entender que o arquivamento requer técnicas precisas e conscientes a todos os profissionais. Isso significa que o suporte correto e a acessibilidade permitem a agilidade na consulta e, consequentemente, auxilia na tomada de decisões (Schellenberg, 2006). Dessa forma, é importante compreender os aspectos principais que compõem as atividades de organização de arquivos e como a assessoria pode contribuir para tais atividades no meio organizacional.

Diante das transformações tecnológicas e econômicas, as organizações necessitam sistematizar as informações e tratá-las por meio da gestão documental. O grande número de informações e consequentemente, suas classificações permitem o registro das atividades organizacionais e tornam-se documentos. Com isso, há a preocupação que esses registros sejam ordenados, preservados e acessíveis aos profissionais que deles precisarem, surgindo, então, os arquivos. Sob esse enfoque, a gestão de documentos possui um papel relevante na administração das organizações (Paes, 2004).

O arquivo é imprescindível para o registro da memória da instituição e ainda faltam conhecimentos técnicos necessários às pessoas responsáveis pelo tratamento do arquivo (Paes, 2004). Neste sentido, o profissional de secretariado executivo, conhecedor de técnicas de arquivos, pode contribuir para a organização do fluxo documental e também assessorar as atividades arquivísticas.

Por isso, a proposição de um projeto de extensão acadêmica de assessoria em arquivos teve o propósito de auxiliar a organização no planejamento, organização, manutenção e controle dos seus arquivos. Ao mesmo tempo, o projeto proposto pretendeu combinar a teoria e a prática das técnicas secretariais e aproximar os acadêmicos de secretariado executivo ao mercado de trabalho e à comunidade, através da assessoria em arquivos.

Assim, a partir do projeto de extensão citado indagou-se: "Como a assessoria em arquivos pode contribuir para a formação do profissional de secretariado executivo?’. 
Nesse contexto, o objetivo geral foi relatar a percepção e experiência dos acadêmicos de Secretariado Executivo de uma universidade pública do Paraná durante a participação no projeto de extensão Assessoria Executiva em Arquivos.

Importante destacar que o trabalho do secretário executivo inclui atividades de assessoria e busca a harmonia entre conhecimentos, teorias, práticas e relações no ambiente organizacional (Nonato Júnior, 2009). Com isso, assessorar em arquivos requer conhecimento de técnicas e principalmente habilidades para orientar e acompanhar as atividades, visto que são funções de domínio do secretário executivo. Assim, os objetivos específicos foram: a) identificar as percepções acadêmicas a respeito da experiência da assessoria em arquivos e b) evidenciar o profissional de secretariado executivo como gestor documental nas organizações.

Para tanto, adotou-se a abordagem qualitativa, com a técnica de observação e coleta de entrevistas de sete participantes do projeto proposto. Após o tratamento dos dados, foi realizada análise de conteúdo, com base nos fragmentos das entrevistas e na revisão da literatura.

Este artigo está estruturado em seis capítulos, sendo o primeiro destinado a introdução, o segundo e terceiro trata da revisão da literatura; o quarto capítulo relata a metodologia; o quinto segue com a análise e discussão dos resultados e, por fim, o sexto traz as considerações finais.

\section{As possibilidades da extensão universitária}

A função da universidade está voltada para a interação ensino-pesquisa-extensão, pois além de formar profissionais competentes, também desempenha suas funções sociais ao se interligar com a comunidade. Conforme menciona Severino (2007, p. 31), “[...] O que se desenrola no interior da Universidade, tanto do ponto de vista da construção do conhecimento, sob o ângulo da pesquisa, como de sua transmissão, sob o ângulo do ensino, tem a ver diretamente com os interesses da sociedade".

Uma das formas de interação da universidade com a sociedade ocorre com a extensão universitária, na qual um dos principais resultantes da extensão universitária é a relação entre os diversos saberes com a realidade da comunidade, permitindo um conhecimento abrangente (Jenize, 2004).

A extensão universitária pode ser entendida como "instrumento a ser utilizado pela Universidade para a efetivação do seu compromisso social. A construção do conceito de extensão tem como base persuadir a Universidade e a comunidade proporcionando benefícios 
e adquirindo conhecimentos para ambas as partes" (Rodrigues, Prata, Batalha, Costa, \& Passos Neto, 2013, p. 142).

Nesse contexto, a universidade é responsável pela formação dos profissionais e a transmissão do conhecimento, na qual o graduando precisa ampliar seus conhecimentos além da sala de aula (Sousa, Barros, \& Agostinho Filho, 2017). Enquanto isso, a sociedade precisa do conhecimento e, muitas vezes, sente dificuldades para obtê-lo (Biscoli, Alves, Moura, \& Vorpagel, 2012). Como forma de complementar esses interesses, a extensão universitária é apontada como uma possível solução para a interligação entre teoria e prática. Silva e Vasconcelos (2006) argumentam que a formação da universidade precisa ir além do seu ambiente, pois os alunos precisam interligar os conhecimentos científicos com a realidade.

Assim, a universidade deve preocupar-se em inovar suas práticas acrescentando a extensão universitária nos seus currículos. Vaz, Oliveira e Stocco (2014, p. 102), confirmam isso:

A organização dos currículos deve apresentar disciplinas que contemplem as questões políticas e sociais que permeiam esta reflexão e a extensão deve estar entrelaçada com a formação integral do futuro profissional, sendo imprescindível sua interação com a sociedade, para situá-lo historicamente, identificá-lo culturalmente e referenciar a sua formação técnica à realidade.

Da mesma forma, esta ideia evidencia a importância do diálogo entre a comunidade universitária e o meio social, de forma a contribuir na ligação ensino, pesquisa e extensão. De acordo com Silva (2012, p. 158), deve-se prezar pela "busca de perspectivas com validade universal e emancipatória, para criar motivações para fazer emergir os projetos/programas de extensão mais consistentes".

De acordo com Gomes, Figueiredo e Ghedin (2011), o ser humano é capaz de aprender sobre o mundo utilizando processos cognitivos, interpretando e transformando tudo à sua volta, da mesma forma que se modifica também.

Assim, percebe-se que a universidade deve estar pronta para saber lidar com os novos saberes e o dinamismo em que o conhecimento é compartilhado (Santos, 1994). Dessa maneira, acredita-se que a extensão universitária deve ser parte integrante das atividades do meio acadêmico, de forma democrática e participativa. 
2.1 O profissional de secretariado executivo e a assessoria em arquivos

Entender o conceito de documento é primordial para conceituar arquivo e consequentemente, entender sua funcionalidade e as atividades inerentes ao gerenciamento e organização da informação. Conforme cita Schellenberg (2006, p. 41):

Todos os livros, papéis, mapas, fotografias ou outras espécies documentárias, independentemente de sua apresentação física ou características, expedidos ou recebidos por qualquer entidade pública ou privada no exercício de seus encargos legais ou em função das suas atividades e preservados ou depositados para preservação por aquela entidade ou por seus legítimos sucessores como prova de suas funções, sua política, decisões, métodos, operações ou outras atividades, ou em virtude do valor informativo dos dados neles contidos.

A partir da classificação dos documentos é possível agrupá-los num arquivo que servirá para manutenção da ordem e da consulta imediata, além de preservar a história da instituição. De acordo com as autoras Varela e Neumann (2011, p. 37):

O arquivo é o conjunto de documentos que foram desenvolvidos ou selecionados por uma empresa ou pessoa, que os mantêm em ordem para futuras pesquisas se necessitar em algum momento dos dados. Esses documentos podem ser classificados como públicos (federal, estadual e municipal), institucionais (escolas, igrejas, sociedades, associações), comerciais (empresas, corporações, companhias) e pessoais (fotos, e-mail, trabalhos).

Quando se trata de arquivo, remete-se a sua importância para a administração por fornecer informações importantes para o desenvolvimento da instituição e, principalmente, por tornar acessível o documento para quem dele precisa (Varela \& Neumann, 2011). Assim, a gestão documental pode ser entendida como "um conjunto de procedimentos técnicos e operacionais referentes às atividades de produção, tramitação, classificação, avaliação e arquivamento dos documentos nas fases corrente e intermediária, visando a sua eliminação ou recolhimento ao Arquivo Permanente" (Pnage, 2007, p. 1).

Nesse contexto, é notório que, na sociedade contemporânea, a agilidade das informações influi nos processos decisórios e diferem aspectos competitivos no mercado. A organização de arquivos não significa simplesmente a arrumação dos documentos nas prateleiras, mas envolve a gestão efetiva dos documentos desde a elaboração, a tramitação, a consulta, a eliminação ou a guarda destes.

Segundo a Lei n. 8.159, de 08 de janeiro de 1991, que constitui a Política Nacional de Arquivos, o ciclo de vida dos documentos trata do uso, guarda, eliminação, destinação final dos documentos. Tal legislação estabelece diretrizes para o gerenciamento dos arquivos, tanto das 
empresas públicas quanto privadas (Zwirtes \& Durante, 2007). Com isso, as organizações precisam adequar-se ao que a lei prevê e, ao mesmo tempo, administrar o arquivo com transparência e agilidade que o mercado exige.

No ciclo de vida do arquivo, a fase corrente é "constituída de documentos em curso ou consultados frequentemente" (Paes, 2004, p. 21) e devem ser mantidos, segundo Camargo, Bellotto e Botani, (1996, p. 6) "juntos aos seus órgãos produtores em razão da sua vigência e da frequência com que são consultados”.

De acordo com Beltrão e Passos (1991, p. 124), os arquivos intermediários ou de segunda idade "reúnem documentos que deixaram de ser frequentemente consultados, mas que devem permanecer acessíveis, por tratarem de assuntos que auxiliam na solução de problemas cotidianos". A terceira idade, ou permanente, são considerados os documentos que possuem valor histórico e comprobatório e perderam seu valor administrativo (Paes, 2004).

A organização e administração do arquivo necessitam de várias etapas de trabalho como o levantamento de dados; análise dos dados coletados; planejamento e implantação e acompanhamento. Na fase de levantamento de dados, é importante levar em consideração as normas e diretrizes da organização; conhecer o seu contexto; perceber o gênero dos documentos e verificar as pessoas envolvidas no processo e os aspectos estruturais disponíveis.

A análise dos dados reflete a prática operacional e as constatações dos pontos fortes e fracos do processo de arquivamento, podendo estabelecer um diagnóstico a fim de avaliar e estabelecer melhorias. Na etapa do planejamento, deve ser elaborado um plano constando a estrutura da instituição; materiais de suporte; recursos humanos; escolha de métodos de arquivamento; normas e procedimentos a serem adotados, etc.

Por último, a implementação e o acompanhamento envolvem verificar se as normas estão sendo seguidas e quais as lacunas devem ser melhoradas, além da conscientização e do treinamento daqueles que utilizam e trabalham com o arquivo (Paes, 2004).

Cabe ressaltar que em todas as etapas da organização do arquivo, o profissional de secretariado executivo pode contribuir orientando as melhores técnicas e procedimentos a serem adotados e acompanhar e dar suporte na implantação do arquivo, através da assessoria. Corroborando a esta ideia, Piccoli, Moreira e Martins (2017, p. 99) argumentam que

a gestão documental é uma que a gestão documental é uma atividade que requer atenção e zelo por parte do profissional encarregado, esperando-se do profissional de secretariado, nessa função, que atue no sentido de incorporar à organização uma nova perspectiva, no sentido de contribuir com 
novas possibilidades de atuação e também, que desenvolva habilidades gerenciais de planejamento, execução de tarefas e controle.

O termo assessoria remete-se aos primórdios de 1500 a.C, com o trabalho dos assessores no exército e depois ao longo da história percebe-se a figura do escriba, que eram intelectuais que prestavam assessorias ao exército ajudando nos planos de guerra, leis, tradução de escritos, entre outros (Nonato Júnior, 2009). Assim, nota-se que o trabalho secretarial se assemelha ao do antigo escriba, que assessorava e desempenhava funções de apoio, conforme as demandas.

Nonato Júnior (2009) descreve o que ele chama de ciências da Assessoria. Para o autor, "ciências da assessoria instauram-se a partir da complexidade dos conhecimentos produzidos e gerenciados pelos profissionais assessores" (Nonato Júnior, 2009, p. 42). Trazendo o conceito para o profissional de secretariado podemos dizer que pensar estrategicamente é fazer com que novas estratégias sejam estabelecidas para facilitar o trabalho do executivo. Assim, o assessor precisa agir estrategicamente para fornecer apoio, pois o principal papel do Assessor é facilitar o trabalho dos superiores hierárquicos.

Conforme explicam Varela e Neumann (2011, p. 45),

o profissional secretário executivo bem informado e com um diferencial na área de arquivologia e gestão documental pode tornar uma empresa mais bem estruturada e organizada, voltada para as necessidades do mercado, sendo capaz de transmitir uma imagem de modernidade, inovação e excelência para todos os que utilizam os seus serviços.

Diante disso, o secretário executivo, detentor de técnicas que possibilitam habilidades em arquivo, pode atuar na assessoria em diversos setores, públicos ou privados. A prática do secretariado concede ao profissional orientar e acompanhar a implementação de planos de arquivo, bem como compartilhar seus conhecimentos adquiridos. Seu currículo pode contemplar as principais técnicas de elaboração, organização, manutenção e controle dos arquivos, bem como o uso da tecnologia como suporte às atividades arquivísticas.

\section{Metodologia}

Para esta pesquisa, utilizou-se a abordagem qualitativa, que procura compreender os fenômenos de acordo com as perspectivas dos sujeitos, ou seja, dos participantes da situação estudada (Godoy, 1995).

Dessa forma, como estratégia de pesquisa realizou-se o estudo de caso, que consiste numa "investigação empírica que investiga um fenômeno contemporâneo dentro de seu 
contexto da vida real, especialmente quando os limites entre o fenômeno e o contexto não estão claramente definidos" (Yin, 2001, p. 32). Assim, esta pesquisa pode ser classificada como descritiva, por apresentar “[...] um relato detalhado de um fenômeno social [...]” (Godoy, 2010, p. 124).

Este estudo centrou-se nas perspectivas acerca do projeto de extensão Assessoria Executiva em Arquivos, realizado no período de abril de 2016 a janeiro de 2017.

O projeto envolveu discentes do curso de Secretariado Executivo de uma Instituição de Ensino Superior do Paraná, com a supervisão de uma docente do curso de Secretariado Executivo. Os participantes fizeram o levantamento de dados, diagnóstico e proposição de um plano de ação de arquivos à organização tomadora do serviço. Além disso, as atividades realizadas referiram-se às orientações quanto ao planejamento; organização; manutenção e controle de arquivos organizacionais.

Nesse contexto, realizaram-se entrevistas semiestruturadas (Flick, 2004) com 7 participantes discentes do projeto, no intuito de verificar a percepção dos mesmos a respeito do projeto desenvolvido, sendo que a escolha dos entrevistados ocorreu por acessibilidade.

Além disso, a observação participante contribuiu na elaboração da análise e considerações pertinentes à pesquisa realizada. Esse tipo de observação possibilita ao pesquisador e aos participantes criar um ambiente favorável à confiança, no qual os participantes sentem-se à vontade para compartilhar experiências (Paterson, Bottorff, \& Hewat, 2003).

Nesse sentido, após a coleta dos dados, utilizou-se a análise de conteúdo (Bardin, 2004), na qual procurou-se triangular os dados com o referencial teórico e observações realizadas. A análise e discussão dos resultados foram apresentados conforme os itens: Relato das Atividades do Projeto de Extensão Assessoria Executiva em Arquivos e Participação dos Acadêmicos no Projeto de Extensão.

\section{Análise e discussão dos resultados}

Nesta seção apresentou-se os relatos dos participantes do projeto de extensão Assessoria em Arquivos, bem como as atividades extensionistas do projeto, contextualizados com o referencial teórico e o objetivo almejado na pesquisa. 
Vale mencionar que foram coletados os relatos dos discentes do curso de Secretariado Executivo, sendo estes nominados como P1, P2, P3, P4, P5, P6 e P7, como forma de garantir o sigilo da identidade dos respondentes.

5.1 Relato das atividades do projeto de extensão assessoria executiva em arquivos

As atividades do projeto de extensão Assessoria Executiva em Arquivos iniciaram a partir das reuniões de planejamento nos meses de junho, julho, agosto e setembro de 2016.

A execução do projeto iniciou a partir do contato com o setor jurídico de uma Instituição de Ensino Superior. Nesse sentido, a primeira reunião aconteceu no dia 24 de outubro de 2016, com a participação dos integrantes do projeto e da equipe do setor atendido.

As reuniões para o planejamento das atividades aconteceram nos meses de outubro a novembro de 2016. Foi estabelecido um cronograma das visitas para o desenvolvimento das atividades, incluindo o levantamento de dados para a elaboração do diagnóstico e do plano de ação, bem como as reuniões para apresentação e acompanhamento das atividades desenvolvidas. Nesse sentido, Paes (2004) afirma que o levantamento de dados requer o exame dos estatutos e regulamentos que regem a instituição atendida, além da verificação de características como gênero, espécie, volume, registros e conservação dos documentos, conforme exemplificado na Figura 1. 
Figura 1 - Fluxograma das atividades do projeto de extensão

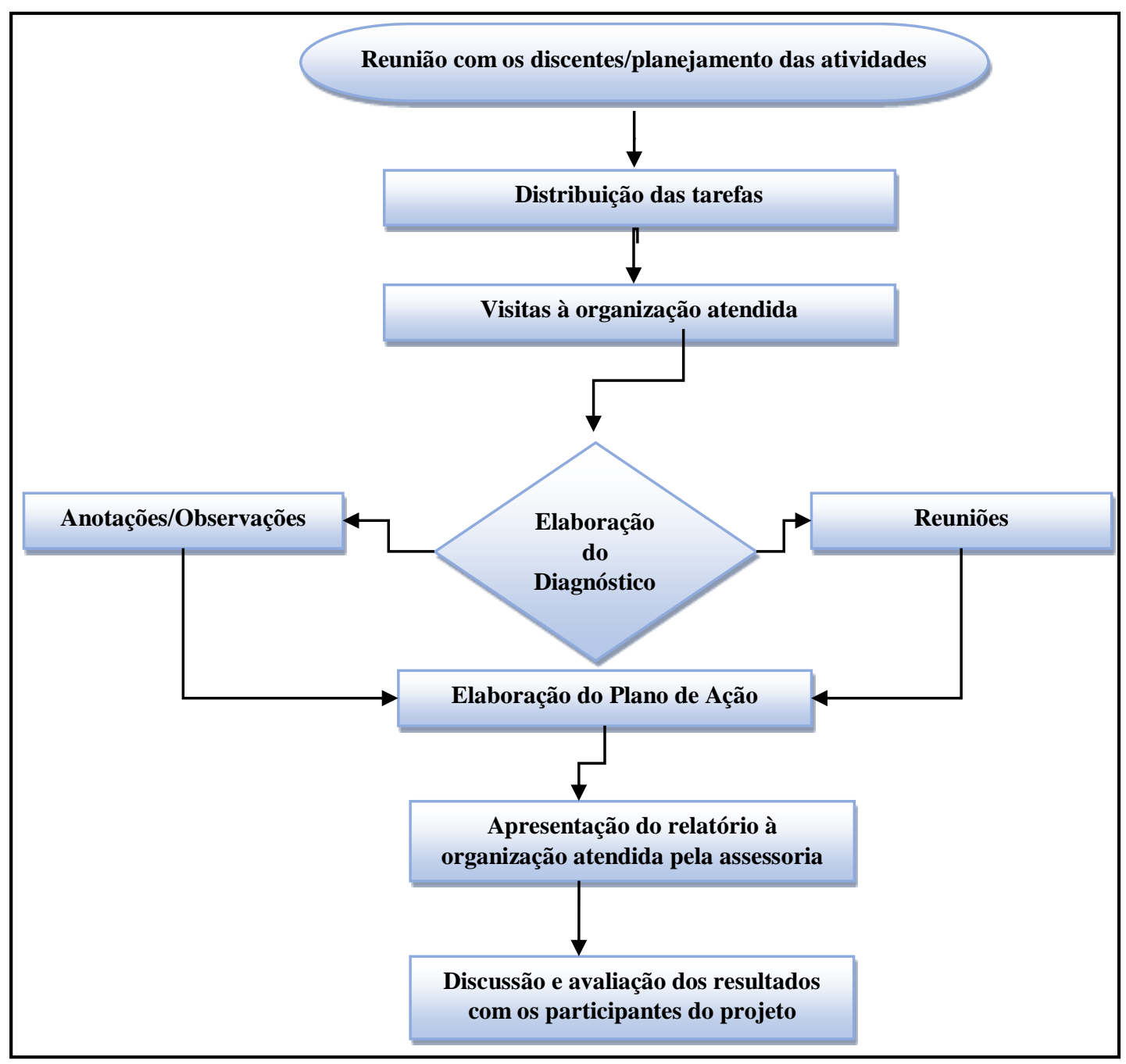

Fonte: Elaborado pela autora com base nas atividades do projeto de extensão (2018).

Nesse contexto, as visitas aconteceram de acordo com as datas previstas e tiveram duração média de uma hora. Para isso, as tarefas foram distribuídas entre os 13 alunos participantes do projeto: a primeira composta por seis integrantes, responsável por fazer as observações, anotações e entrevistas durante as visitas. A segunda, com sete participantes, responsável pela elaboração escrita do diagnóstico e do plano de ação. Essa divisão foi feita para facilitar o desenvolvimento das atividades e, também, foi acordado com o setor atendido que apenas seis integrantes fariam as visitas, mediante assinatura de termo de sigilo elaborado pelo próprio atendido.

Dessa forma, com a colaboração de todos os participantes, foi elaborado um relatório contendo o diagnóstico organizacional e um plano de ação para o arquivo da organização 
atendida, a partir das observações, das discussões em todas as fases do cronograma. Nesse sentido, Paes (2004, p. 36) argumenta que o diagnóstico funciona como "uma constatação dos pontos de atritos, falhas, ou lacunas existentes no complexo administrativo, enfim, das razões que impedem o funcionamento eficiente do arquivo".

Durante o projeto foram realizadas reuniões com os participantes visando o diálogo e participação conjunta. Essas reuniões ocorreram mensalmente tendo como local o Laboratório de Técnicas Secretariais do Curso de Secretariado Executivo da Instituição de Ensino. Ainda foi criado um arquivo eletrônico, no qual os participantes podiam elaborar os relatórios, além da criação de um grupo numa rede social para auxiliar na comunicação entre todos.

Além disso, o setor, no qual ocorreu o atendimento, disponibilizou uma sala para realização das visitas, sendo que nesta sala estão armazenados os arquivos e funciona a secretaria.

O relatório contendo o plano de ação foi apresentado ao setor atendido, no qual a equipe de discentes responsável pelas visitas apontou as principais sugestões e observações realizadas, assim, o setor acolheu essas contribuições.

A avaliação dos resultados do projeto de extensão deu-se por meio de discussões em grupo entre os participantes, além da avaliação positiva da organização atendida, indicando que o projeto alcançou seus objetivos traçados, que consistiam em realizar assessoria e apoio às instituições na organização dos arquivos, com vistas ao aprendizado acadêmico das práticas secretariais e oportunizar aos acadêmicos extensionistas, convivência com a realidade social e prática profissional.

Nesse contexto, a partir das entrevistas e da observação participante verificou-se a percepção dos discentes a respeito da participação no projeto.

\subsection{A participação dos acadêmicos no projeto de extensão}

Durante o projeto de extensão, observou-se o comprometimento dos acadêmicos no que se refere à participação das reuniões e discussões sobre a elaboração do diagnóstico e do plano de ação arquivístico.

Assim, questionou-se como foi a experiência em participar do projeto Assessoria em Arquivos e elaborou-se o Quadro 1 com as falas dos participantes. 
Quadro 1 - Participação no Projeto Assessoria em Arquivos

\begin{tabular}{|c|c|}
\hline Participantes & Como foi a experiência em participar do projeto Assessoria em Arquivos? \\
\hline P1 & $\begin{array}{l}\text { "Foi muito boa, pois com o projeto analisamos que os arquivos merecem ser valorizados e } \\
\text { inovados". }\end{array}$ \\
\hline $\mathrm{P} 2$ & $\begin{array}{l}\text { "Foi interessante, pois foi possível ter um contato além da teoria aprendida em sala de } \\
\text { aula". }\end{array}$ \\
\hline P3 & $\begin{array}{l}\text { "Foi uma experiência boa, pois adquirimos bastante conhecimentos em relação a gestão de } \\
\text { documentos". }\end{array}$ \\
\hline P4 & $\begin{array}{l}\text { "Excelente, pois adquiri conhecimentos que são de grande importância para o meu } \\
\text { trabalho cotidiano". }\end{array}$ \\
\hline P5 & $\begin{array}{l}\text { "Foi algo muito compensador, são experiências a serem levadas para toda vida, além do } \\
\text { diferencial para o curso de secretariado executivo". }\end{array}$ \\
\hline P6 & $\begin{array}{l}\text { "Muito gratificante pelo conhecimento intelectual adquirido e principalmente o } \\
\text { conhecimento prático". }\end{array}$ \\
\hline P7 & $\begin{array}{l}\text { "Foi ótima, pois pude observar os conhecimentos obtidos em sala de aula através do } \\
\text { projeto". }\end{array}$ \\
\hline
\end{tabular}

Fonte: Elaborado pela autora a partir dos relatos dos entrevistados (2017).

De acordo com os discursos dos acadêmicos do projeto, a participação no projeto foi benéfica, pois assimilaram novos conhecimentos e partilharam experiências. Segundo Gomes, Figueiredo e Ghedin (2011, p. 10) “O ensino com pesquisa é capaz de mobilizar vários processos cognitivos, isto porque falar de processos cognitivos implica a compreensão sobre nossa capacidade de pensar, aprender e construir significados, de perceber o mundo que nos rodeia".

Nesse contexto, notou-se a participação discente além do ambiente acadêmico prático (Sousa et al., 2017), ou seja, os alunos conseguiram visualizar o alinhamento entre o conhecimento teórico e o conhecimento prático. Isso ficou evidente na elaboração escrita do plano de ação, no qual os discentes a partir das observações realizadas in loco e da literatura que trata da gestão documental, propuseram melhorias para a organização atendida. Nesse sentido, destaca-se a função da universidade em proporcionar conhecimento além do ambiente da sala de aula, ou seja, os acadêmicos conseguiram ter contato com a realidade (Silva \& Vasconcelos, 2006).

Os entrevistados também foram questionados se a prática da assessoria em arquivos durante o projeto trouxe novos conhecimentos e quais foram eles. Nesse sentido, todos os participantes concordaram que obtiveram novos conhecimentos. Dessa maneira, notou-se que o trabalho do secretário executivo, no ato de assessorar, integra conhecimentos teóricos e práticos, além do desenvolvimento de técnicas e habilidades desse profissional nas organizações (Nonato Júnior, 2009). 
Assessoria executiva em arquivos: relato das percepções acadêmicas de um projeto de extensão universitária

Nesse contexto, os entrevistados expressaram suas opiniões sobre como o profissional de secretariado executivo pode contribuir com a gestão documental nas organizações, conforme apresentadas no Quadro 2.

Quadro 2 - Profissional de Secretariado Executivo e a Gestão Documental

\begin{tabular}{|c|c|}
\hline Participantes & $\begin{array}{l}\text { Como o profissional de secretariado executivo pode contribuir com a gestão } \\
\text { documental nas organizações? }\end{array}$ \\
\hline P1 & $\begin{array}{l}\text { "O profissional de secretariado pode contribuir com uma das principais características que } \\
\text { é ter organização, auxilia para manter a ordem, planejamento e colabora nas rotinas da } \\
\text { organização ou setor que trabalha". }\end{array}$ \\
\hline $\mathrm{P} 2$ & $\begin{array}{l}\text { "Ele pode contribuir na organização, na escolha do melhor método de arquivamento e } \\
\text { indicar quais os melhores equipamentos para manter os arquivos seguros e conservados } \\
\text { dentro dos recursos das organizações". }\end{array}$ \\
\hline P3 & $\begin{array}{l}\text { "Esse profissional pode contribuir através de sua assessoria, pois possui várias habilidades } \\
\text { para organizar os documentos e o acesso rápido a eles". }\end{array}$ \\
\hline $\mathrm{P} 4$ & $\begin{array}{l}\text { "Como um bom profissional, pode organizar de várias maneiras os documentos (assuntos, } \\
\text { datas, ordem alfabética, etc.), tudo de acordo com a necessidade da organização". }\end{array}$ \\
\hline P5 & $\begin{array}{l}\text { "O profissional de secretariado executivo está apto a trabalhar com arquivos em qualquer } \\
\text { tipo de instituição, pois ele é um agente facilitador". }\end{array}$ \\
\hline P6 & $\begin{array}{l}\text { "Nos processos de organização de documentos para destinar a melhor forma de } \\
\text { arquivamento, trazendo melhorias e diminuindo o tempo para busca de cada documento". }\end{array}$ \\
\hline P7 & $\begin{array}{l}\text { "O profissional de secretariado executivo pode contribuir nas organizações com a gestão } \\
\text { documental na medida em que suas ações possibilitam a melhoria no processo de } \\
\text { arquivamento, facilitando o armazenamento e a busca por documentos". }\end{array}$ \\
\hline
\end{tabular}

Fonte: Elaborado pela autora a partir dos relatos dos entrevistados (2017).

Diante dos fragmentos coletados, notou-se que os acadêmicos reconhecem o perfil e habilidades do trabalho do secretário executivo como gestor documental. Isto fica perceptível no discurso dos participantes do projeto. Nessa perspectiva, concordou-se com Varela e Neumann (2011) que o profissional de secretariado bem informado pode atuar com diferencial em suas atividades, estimulando soluções e promovendo modernidade e inovação no ambiente em que atua.

Além disso, os entrevistados mencionaram que os conhecimentos práticos e teóricos na área de secretariado concedem ao profissional orientar e acompanhar a implementação de planos de arquivo nas organizações. Complementando-se a esta ideia, Montezano, Souza e Baeta (2015, p. 125) acreditam que os profissionais de secretariado executivo "devem estar preparados para assessorar executivos, gerenciar setores e pessoas, gerir fluxo de informação e utilizar novas tecnologias em um cenário de mudanças culturais, econômicas, políticas, sociais e profissionais".

Nesse contexto, notou-se que o projeto proporcionou aos participantes a oportunidade de relacionar a teoria, oportunizada pelos conhecimentos obtidos em sala de aula, com a prática, 
no desenvolvimento das atividades do projeto, além de verificar as dificuldades nas rotinas dos profissionais que trabalham com arquivos. Isso foi observado durante as aulas da disciplina de Técnicas Secretariais II, nas quais os alunos trouxeram exemplos práticos observados durante as visitas à organização atendida pelo projeto. Na visão de Sousa et al. (2017, p. 71) “a formação acadêmica, quando atrelada a instrumentos que ultrapassam a extensão da Universidade, é enriquecida com conceitos e práticas éticas, sociais e culturais, além da educacional, conseguindo então atingir o objetivo dessa instituição de ensino". Além disso, o projeto contribuiu na assimilação dos conhecimentos secretariais e no contexto das práxis na formação do profissional de secretariado executivo.

\section{Considerações Finais}

As atividades do projeto de extensão Assessoria Executiva em Arquivos permitiram estabelecer uma aproximação com o setor administrativo da organização atendida, tornando-se uma ferramenta importante para a formação em secretariado e o desenvolvimento entre ensino e aprendizagem.

Vale mencionar que o projeto alcançou seu objetivo, ao relatar a experiência vivenciada com a atividade extensionista. Além disso, propiciou o exercício da prática entre os acadêmicos do curso de Secretariado Executivo, através da assessoria executiva prestada, das discussões dos grupos de trabalho, além dos encontros informais entre as participantes, proporcionando a construção do conhecimento em arquivos.

As atividades realizadas despertaram o interesse dos acadêmicos, participantes do projeto, pela arquivologia e trouxe, também, o reconhecimento do projeto tanto da comunidade acadêmica quanto da organização atendida.

Durante o desenvolvimento das atividades extensionistas, as habilidades empreendedoras do profissional de secretariado foram percebidas pela organização atendida, tanto na organização das atividades quanto na apresentação do plano de ações, realizadas pelos discentes. Isso trouxe maior notoriedade tanto para o curso de Secretariado Executivo quanto para os profissionais e suas carreiras.

Assim, o projeto trouxe uma perspectiva de continuidade, com novas propostas extensionistas ampliadas para outros tipos de organizações e contextos, objetivando inserir o 
profissional de secretariado executivo no mercado de trabalho, contribuir com sua formação acadêmica e profissional.

Certamente a realização do projeto contribuiu na melhoria da formação de futuros profissionais de secretariado executivo, além de demonstrar a importância dos arquivos nas organizações, contribuindo para o desenvolvimento do ensino, da pesquisa e da metodologia de ensino de arquivística. Isso ficou comprovado pela dedicação e empenho dos discentes, observados durante a realização da assessoria em arquivos, e, também, os relatos dos mesmos apontaram que a atividade extensionista trouxe novos conhecimentos e experiência.

\section{Referências}

Bardin, L. (2004). Análise de Conteúdo. Lisboa, Edições 70.

Beltrão, M., \& Passos, E. I. (1991). Prática de secretariado: recepção, telefonia, correspondência, arquivística, reprografia. (2a ed.). São Paulo: Editora Atlas.

Biscoli, F. R. V., Alves, J. K. D., Moura, J. E. de, \& Vorpagel, J. S. (2012). A extensão universitária e os acadêmicos de Secretariado Executivo da Unioeste/Campus Toledo. Revista Conexão, 8(2). Recuperado em 12 novembro, 2017 de http://www.revistas2.uepg.br/ index.php/conexao/article/view/4558.

Camargo, A. M. A, Bellotto, H. L., \& Botani, A. S. L. (1996). Dicionário de Terminologia Arquivística. Associação dos Arquivistas Brasileiros. Núcleo Regional de São Paulo.

Flick, U. (2004). Entrevistas semiestruturadas. In: Flick, U. Uma introdução à pesquisa qualitativa. (2a ed.). Porto Alegre: Bookman.

Godoy, A. S. (1995). Introdução à pesquisa qualitativa e suas possibilidades. Revista de Administração de Empresas, São Paulo, 35(2), 57-63. Recuperado em 15 janeiro, 2017 de http://rae.fgv.br/sites/rae.fgv.br/files/artigos/10.1590_S003475901995000200008.pdf.

Godoy, A. S. (2010). Estudo de caso qualitativo. In: Godoi, C. K. (Org.). Pesquisa Qualitativa em Estudos Organizacionais. São Paulo: Saraiva, pp.115-146.

Gomes, R. C. S., Figueiredo, A. M. R., \& Ghedin, E. (2011). Os processos cognitivos mobilizados pelo ensino com pesquisa na pedagogia universitária. Rev. Areté, 4(6), Manaus, 9-13. 
Jenize, E. (2004). As Práticas Curriculares e a Extensão Universitária. In: Congresso Brasileiro De Extensão Universitária, 2., Belo Horizonte. Anais... Belo Horizonte. Recuperado em 12 novembro, 2017 de http://br.monografias.com/trabalhos-pdf901/as-practicascurriculares/as-practicas-curriculares.pdf.

Montezano, N. S., Souza, R. B. de, \& Baeta, O. V. (2015). A importância da gestão da informação para a atuação profissional do secretário executivo - uma revisão de literatura nacional integrativa. R.G.Secr.,GESEC, São Paulo, 6(2), 111-133, maio./agosto.

Nonato Júnior, R. (2009). Epistemologia e Teoria do Conhecimento em Secretariado Executivo: a fundação das ciências da assessoria. Fortaleza: Expressão Gráfica.

Paes, M. L. (2004). Arquivo: teoria e prática. (3a ed.). Rio de Janeiro: FGV.

Paterson, B. L., Bottorff, J. L., \& Hewat, R. (2003). Blending observational methods: possibilities, strategies and challenges. International Journal of Qualitative Methods, 2(1), 29-38.

Piccoli, A. L., Moreira, K. D., \& Martins, C. B. (2017). O profissional de secretariado e a gestão documental: processo de implantação de arquivo digital em uma organização do setor privado. Pesquisa Brasileira em Ciência da Informação e Biblioteconomia, 12(2).

Programa Nacional de Modernização e Gestão Pública - Pnage. (2007). Título 3: Da documentação e arquivo. 20p. Recuperado em 12 novembro, 2017 de http://www.pnage.pa.gov.br/sites/default/files/4_Documentaçao_e_Arquivo.pdf.

Rodrigues, A. L. L., Prata, M. S., Batalha, T. B. S., Costa, C. L. N. do A., \& Passos Neto, I. de F. (2013). Contribuições da extensão universitária na sociedade. Cadernos de Graduação - Ciências Humanas e Sociais - UNIT, 1(16),141-148.

Santos, B. S. (1994). Pelas mãos de Alice: o social e política na pós-modernidade. Porto, Portugal: Edições Afrontamento.

Severino, A. J. (2007). Metodologia do trabalho científico. (23a ed.). São Paulo: Cortez.

Schellenberg, T. R. (2006). Arquivos modernos, princípios e técnicas. Rio de Janeiro: FGV.

Silva, E. W. da. (2012). Extensão universitária no Rio Grande do Sul: concepções e práticas. Tese (Doutorado em Sociologia) - Universidade Federal do Rio Grande do Sul, Porto Alegre.

Silva, M. S., \& Vasconcelos, S. D. (2006). Extensão universitária e formação profissional: avaliação da experiência das Ciências Biológicas na Universidade Federal de 
Pernambuco. Estudos em Avaliação Educacional, 17(33), jan./abr. Recuperado em 10 setembro, 2017 de http://www.fcc.org.br/pesquisa/publicacoes/eae/arquivos/1280/1280.pdf.

Sousa, R. F. R. de, Barros, C. M. P. de, \& Agostinho Filho, J. C. (2017). Docência e Extensão: projeto "Caminhos do Saber em Secretariado Executivo". Revista Extensão em Ação, 2(14), jul./dez., 67-80. Recuperado em 15 setembro, 2017 de file:///D:/Arquivos\%20Usuario/Downloads/20314-91607-1-PB.pdf.

Varela, K., \& Neumann, S. E. (2011). A importância da arquivologia na profissão de secretário executivo.Secretariado Executivoem Revist@, Passo Fundo, 7, 36-48, jan. Recuperado em $10 \quad$ setembro, $2017, \quad$ de http://www.upf.br/seer/index.php/ser/article/view/2325/1479.

Vaz, C. de F. M., Oliveira, I. R. de., \& Stocco, J. A. P. (2014). A extensão universitária no Secretariado Executivo: algumas contribuições do projeto Super'ação - secretariado vai à escola. Cataventos. Cruz Alta, 1. Recuperado em 15 setembro, 2017, de http://revistaeletronica.unicruz.edu.br/index.php/Cataventos/article/view/565.

Yin, R. K. (2001). Estudo de caso: planejamento e métodos. (2a ed.). Porto Alegre: Bookman. Zwirtes, C. L., \& Durante, D. G. (2007). Gestão documental: atuação do secretário executivo. Secretariado Executivo em Revist@, 3, 1-11. 